\title{
Repair of the Malpositioned Lower Lid
}

\author{
David Chan, MD ${ }^{1}$ Mofiyinfolu Sokoya, MD² Yadranko Ducic, MD, FRCS(C), FACS 3
}

1 Department of Otolaryngology-Head and Neck Surgery, Indiana University School of Medicine, Indianapolis, Indiana

2 Department of Otolaryngology, University of Colorado School of Medicine, Aurora, Colorado

3 Otolaryngology and Facial Plastic Surgery Associates, Fort Worth, Texas
Address for correspondence Yadranko Ducic, MD, FRCS(C), FACS, Otolaryngology and Facial Plastic Surgery Associates, 923 Pennsylvania Avenue, Suite 100, Fort Worth, TX 76104 (e-mail: yducic@sbcglobal.net).

Facial Plast Surg 2017;33:598-605.

\begin{abstract}
Keywords

- lower lid malposition

- ectropion

- entropion

Complications from surgical approaches to the orbit can be associated with debilitating morbidity and negative surgical outcomes. The surgeon must be familiar with the different factors that predispose a patient to these complications and be facile with techniques to avoid them. In this article, the authors discuss the surgical anatomy of the lower eyelid, as well as various complications that result from eyelid surgery, including lower lid retraction, ectropion, entropion, canthal malposition, and midface descent. They also discuss various management techniques that are employed in addressing these complications.
\end{abstract}

Facial fractures can lead to long-term sequelae if not repaired. Complications from surgical approaches can be equally detrimental to the patient. Periorbital approaches via the lower lid can lead to ectropion, entropion, scleral show, canthal malposition, and lid edema. ${ }^{1-6}$ Ectropion can cause epiphora, whereas entropion often causes pain and irritation due to contact between the cilia and cornea. Transcutaneous and tranconjunctival approaches are commonly used to address fractures of the infraorbital rim and orbital floor. The transconjunctival approach is popular among otolaryngologists and ophthalmologists, whereas transcutaneous approaches are more commonly used by oral maxillofacial surgeons and plastic surgeons. ${ }^{7}$ Ridgway et al reported in their meta-analysis that lid complications are highest with the subciliary approach (19.1\%) and lowest with transconjunctival approach (2.1\%). ${ }^{5}$ Raschke et al also found a lower incidence of lower lid malposition via the transconjunctival approach compared with the subciliary approach. ${ }^{8}$ Regardless of approach, complications occur and the facial trauma surgeon must know how to manage these issues. In this article, we will review the common complications of lower lid surgery and their treatment.

\section{Surgical Anatomy}

Successful surgical outcomes require a firm understanding of the complex anatomy and function of the eyelids. The eyelids provide lubrication to the cornea as well as shield it from foreign materials. With every blink, the protective tears are spread over the surface of the cornea. The upper and lower lids are composed of analogous structures that are divided into the anterior, middle, and posterior lamellae. The anterior lamella includes the skin and orbicularis oculi muscle; the middle lamella refers to the orbital septum; and the posterior lamella refers to the retractors, superior or inferior tarsal muscle, tarsus, and the conjunctiva. ${ }^{9}$ Herein, we will discuss the lower lid anatomy in more detail.

The lower lid skin is the most superficial layer of the anterior lamella. Just deep to the skin is the orbicularis oculi muscle. It is formed by concentric muscle fibers divided into orbital and palpebral parts. The orbital portion arises from the medial canthal tendon and then inserts subcutaneously at the lateral aspect. The palpebral portion spans between the medial and lateral canthal tendons. The palpebral portion can be further divided into pretarsal and preseptal parts based on the structures that it lies upon. Medially, the medial canthal tendon forms two heads-one inserts onto the anterior lacrimal crest, while the other inserts more posterior onto the posterior lacrimal crest. Laterally, the fibers condense to form the lateral canthal tendon, which inserts into Whitnall's tubercle, located approximately $4 \mathrm{~mm}$ posterior to the lateral orbital rim (-Fig. 1). ${ }^{9}$

The middle lamella consists of the orbital septum. In the lower lid, the orbital septum fuses with the capsulopalpebral
Issue Theme Aesthetic Management of Upper and Midface Trauma; Guest Editor, Yadranko Ducic, MD, FRCS(C), FACS
Copyright $\odot 2017$ by Thieme Medical Publishers, Inc., 333 Seventh Avenue, New York, NY 10001, USA. Tel: +1(212) 584-4662.
DOI https://doi.org/ 10.1055/s-0037-1608711. ISSN 0736-6825. 


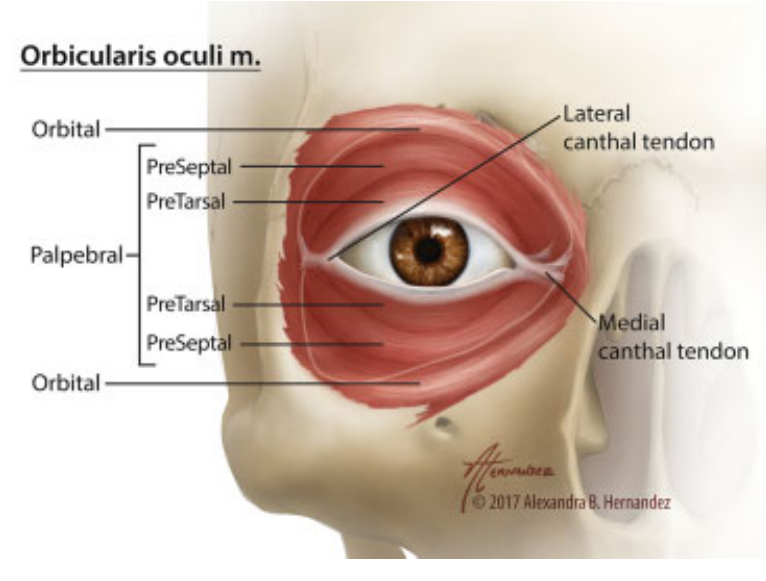

Fig. 1 Anatomy of orbicularis oculi muscle.

fascia approximately $5 \mathrm{~mm}$ inferior to the tarsus. ${ }^{9}$ Just deep to the orbicularis oculi muscle in the lower lid lies the suborbicularis oculi fat (SOOF) pad (-Fig. 2). It is distinct from the orbital fat pads, which are postseptal. The SOOF extends inferiorly to cover the inferior orbital rim. Ptosis of the SOOF can lead to "malar bags." 10 The malar fat pad also descends with age owing to gravity and can result in lower lid descent and malposition.

The posterior lamella of the lower lid consists of the tarsus, the lower lid retractors, and the conjunctiva. The lower lid retractors consist of the capsulopalpebral fascia and the inferior tarsal muscle, which ultimately attaches to the tarsal plate. Some fibers from the lower lid retractors extend through the orbital fat and orbicularis muscle to insert subcutaneously, although not to the degree of the upper

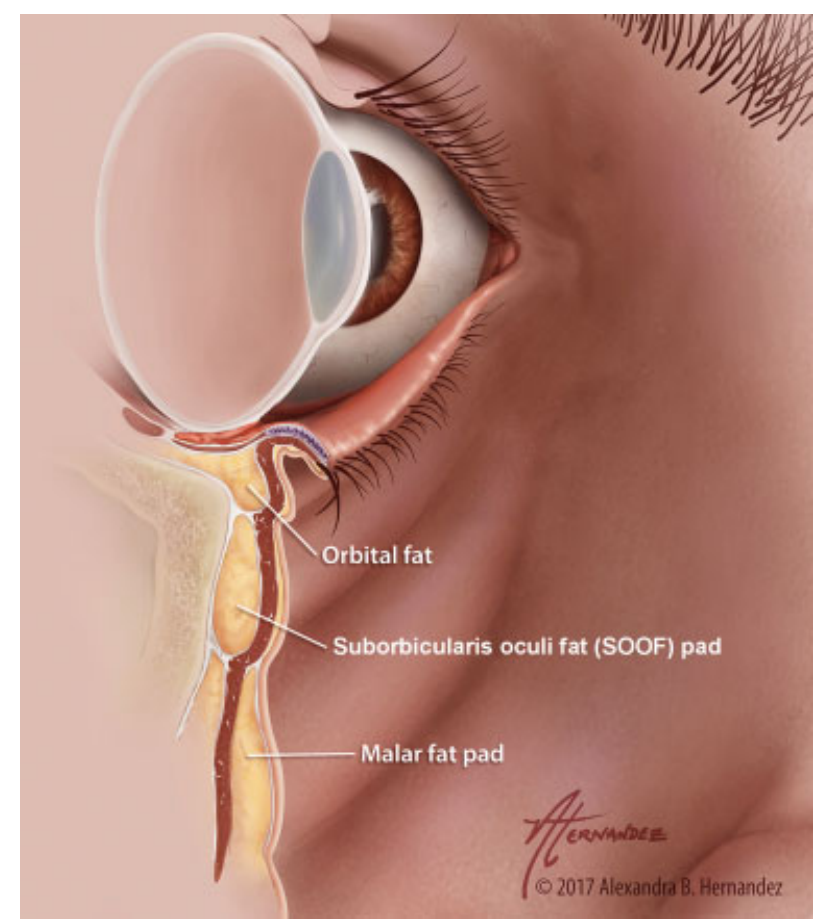

Fig. 2 Lower lid SOOF pad and malar fat pad anatomy. SOOF, suborbicularis oculi fat. lid levator aponeurosis. Loss of the lower lid retractors to the tarsus can result in rotational instability of the lower lid. The lower lid tarsal plate is about half the height of the upper tarsus, measuring 4 to $5 \mathrm{~mm}$, but is similar in horizontal length and thickness.

The lower lid postseptal fat pads are divided into lateral, central, and medial compartments. The lateral and central fat pads are separated by a fascial bad extending from the capsulopalpebral fascia to the inferolateral orbital rim. ${ }^{11}$ The central and medial compartment are separated by the inferior oblique muscle. The paler and firmer medial fat pad is often associated with larger vessels. The inferior oblique originates along the orbital floor approximately $5 \mathrm{~mm}$ posterior to the inferior orbital rim. ${ }^{12}$ Care should be taken to not injure the muscle as it can cause diplopia or strabismus (-Fig. $\mathbf{3}$ ).

\section{Pathophysiology of Lower Lid Retraction}

Lower lid retraction presents with an inferior positioning of the lower lid without eversion or inversion. While other causes may be involved, the most common is due to horizontal laxity of the tarsoligamentous sling or the orbicularis muscle. Other causes of lower lid retraction may be the result of trauma or surgery in which the middle lamella is tethered or the vertical support of the lower lid is weakened due to midface descent.

\section{Lateral Canthal Tendon Laxity}

Lower lid malposition due to lateral canthal laxity may be the result of age, trauma, facial paralysis, congenital, or iatrogenic cause. One can test for lateral canthal tendon laxity by placing a finger over the lateral canthal angle and directing the force in a superior and lateral direction. This will mimic a lateral canthal tendon tightening procedure. If the central lid is appropriately positioned along the inferior limbus, then a tightening procedure may be all that is necessary for the patient.

\section{Middle Lamella Scarring}

Fibrosis can occur between the orbital septum and the capsulopalpebral fascia due to trauma or surgery. The scarring can result in posterior displacement of the orbital fat pads and lead to a hollowing appearance and retraction of the lower lid resulting in scleral show. A vertical traction test can be performed in which the lower lid is pushed upward toward the cornea. If there is resistance to movement, this would suggest middle lamella scarring. ${ }^{13}$

Treatment of middle lamella scarring involves release of the lower lid retractors from the scarred orbital septum. This is performed through a transconjunctival approach where the lower lid retractors are released from the tarsus, followed by separation of the capsulopalpebral fascia from the orbital septum. This will allow the orbital fat to return to its natural position between the two lamellae. A spacer graft is then placed between the inferior tarsal edge and the recessed conjunctiva and capsulopalpebral fascia. This graft allows restoration of the lower lid retractor height. Spacer grafts can be harvested from the hard palate, temporalis fascia, dermis, auricular cartilage, septal cartilage, tarsal grafts, or 


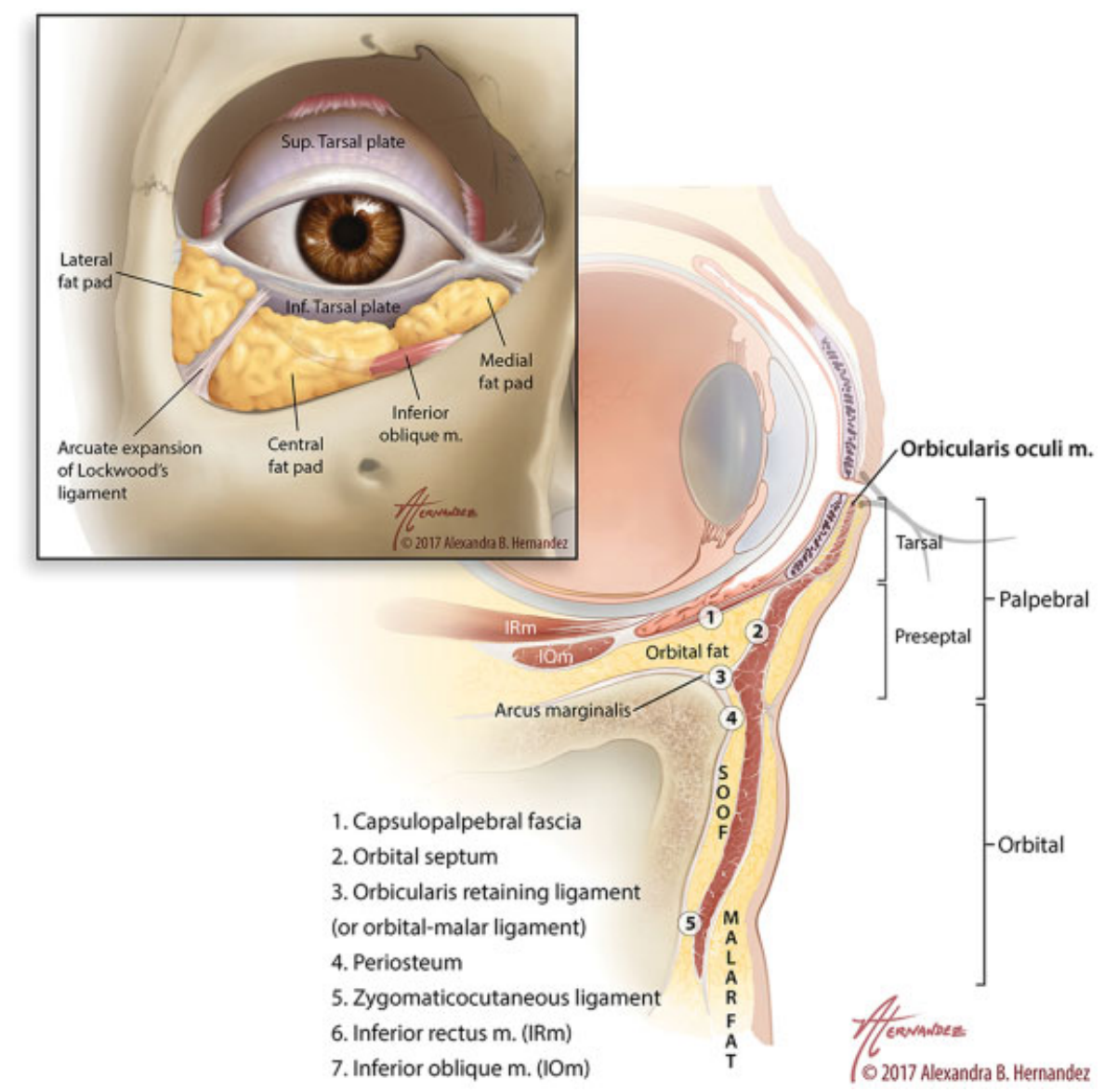

Fig. 3 Sagittal view of lower lid anatomy and fat compartments (inset).

alloplastic implants. The hard palate graft is the gold standard as it closely resembles the tarsus in consistency and structural integrity. ${ }^{14}$

\section{Midface Descent}

The midface changes as one ages, with loss of bony and soft tissue support. Increased laxity of the orbicularis oculi muscle, orbital septum, tarsal plate, as well as the zygomaticus muscles also occur. These multitude of factors result in descent of the malar fat pad as evidenced by a hollowed appearance in the infraorbital region, deepening of the nasolabial fold, and lower lid retraction. ${ }^{15}$ Fractures of the zygomaxillary complex and its treatment can also result in midface descent. This is due to release of periosteal attachments during the wide elevation of the midface tissue to gain access to fixate the fractures. ${ }^{1}$ Treatment of the midface tissue may be required in cases where lateral canthal tightening or spacer treatment does not fully address the malpositioned lower lid.

\section{Ectropion}

Ectropion of the lower lid is characterized by eversion of the lid margin. Types of ectropion include involutional, cicatricial, paralytic, and mechanical. Ectropion can cause epiphora due to punctal eversion, resulting in conjunctival irritation and keratitis due to lagophthalmos. ${ }^{16}$

\section{Involutional Ectropion}

Ectropion of the involutional type is the most common and is the result of horizontal lid laxity secondary to age and disinsertion of the lower lid retractors. ${ }^{17}$ As a person ages, the canthal ligaments and orbicularis muscle may weaken, resulting in increased lid laxity. In addition, the malar fat pad descends with age and midface volume loss may also contribute to the loss of support of the lower lid. Treatment of involutional ectropion requires correction of the lower lid laxity in both horizontal and vertical directions. The most common method of treatment for horizontal laxity is a lateral tarsal strip procedure (-Fig. 4). ${ }^{18}$ Other tightening procedures described in the literature include lateral canthopexy, pentagonal wedge resection, and inferior or lateral retinacular canthoplasty. ${ }^{19-21}$ Patients may present with medial involutional ectropion and suffer from epiphora due to punctal eversion. This can be corrected by a medial conjunctival spindle procedure. ${ }^{22}$ To correct vertical laxity, external and tranconjunctival techniques have been described to identify and reattach Mueller's muscle and the capsulopalpebral fascia to the inferior border of the tarsus. ${ }^{17}$ A posterior approach with a Putterman clamp can also be employed to correct the lower lid ectropion as described by Singa et al in which both the vertical and horizontal components are addressed. ${ }^{23}$ 

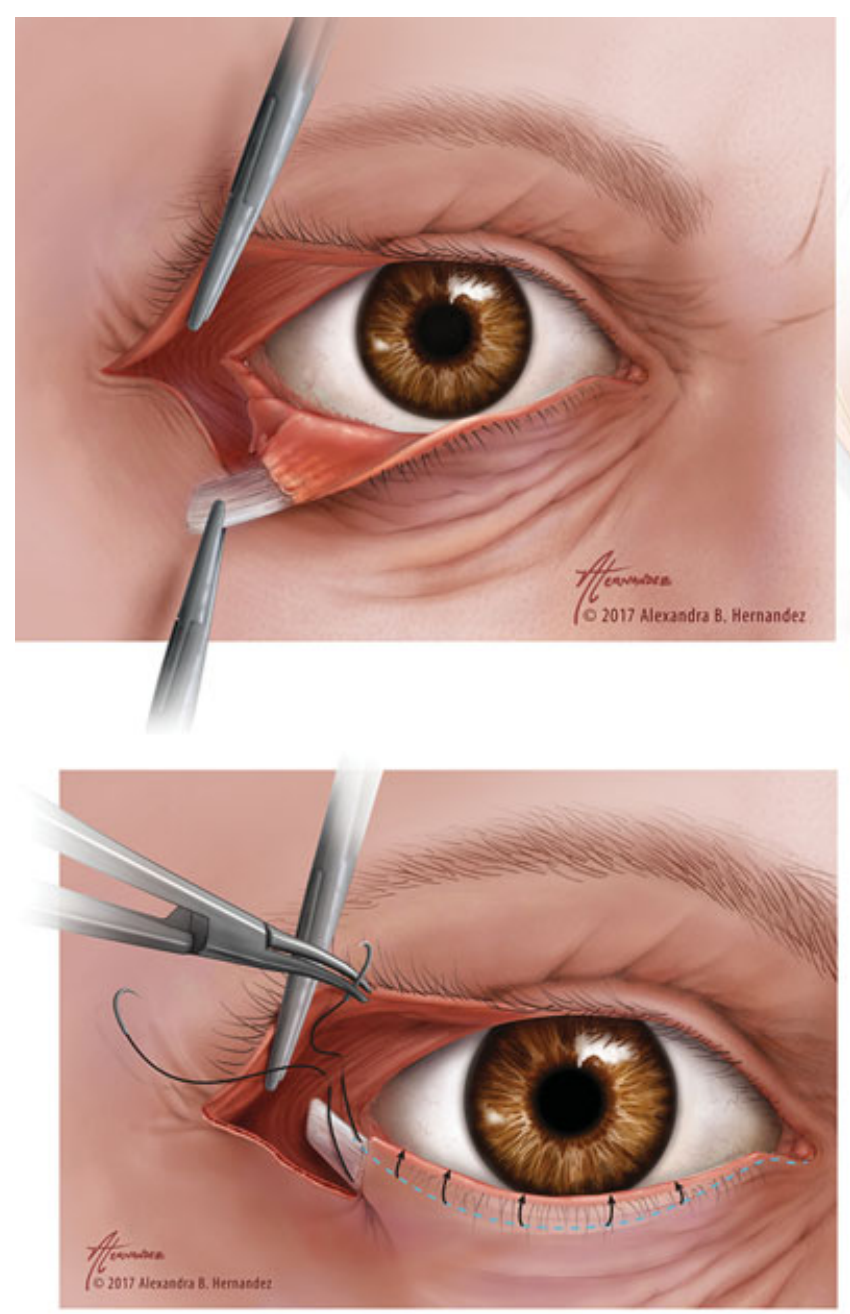

Fig. 4 Lower lid involution ectropion and tarsal strip procedure

\section{Cicatricial Ectropion}

Cicatricial ectropion is due to vertical shortening of the anterior or middle lamella, secondary to lower lid injury or an inflammatory process. Excessive skin and/or muscle removal during transcutaneous lower lid blepharoplasty may result in cicatricial ectropion. The transconjunctival blepharoplasty has a lower risk of ectropion even if skin is removed. If ectropion is noted early in the postoperative period, conservative management may prevent lower lid retraction and eversion. Significant ectropion will require surgical repair. Anterior lamellar shortening due to overresection of skin or scar contracture will require a full thickness skin graft. The skin graft is ideally harvested from the upper lid for best match, but postauricular or supraclavicular skin has been used as well (- Fig. 5). Ectropion due to scar contracture of the orbital septum or adhesion of the middle lamella to the inferior orbital rim will require transconjunctival release of the adhesion and lengthening of the middle lamella with spacer grafts.

\section{Entropion}

Entropion of the lower lid is defined as the inward rotation of the eyelid margin. This can cause irritation to the cornea as the lashes and epithelium of the lid margin continuously rub

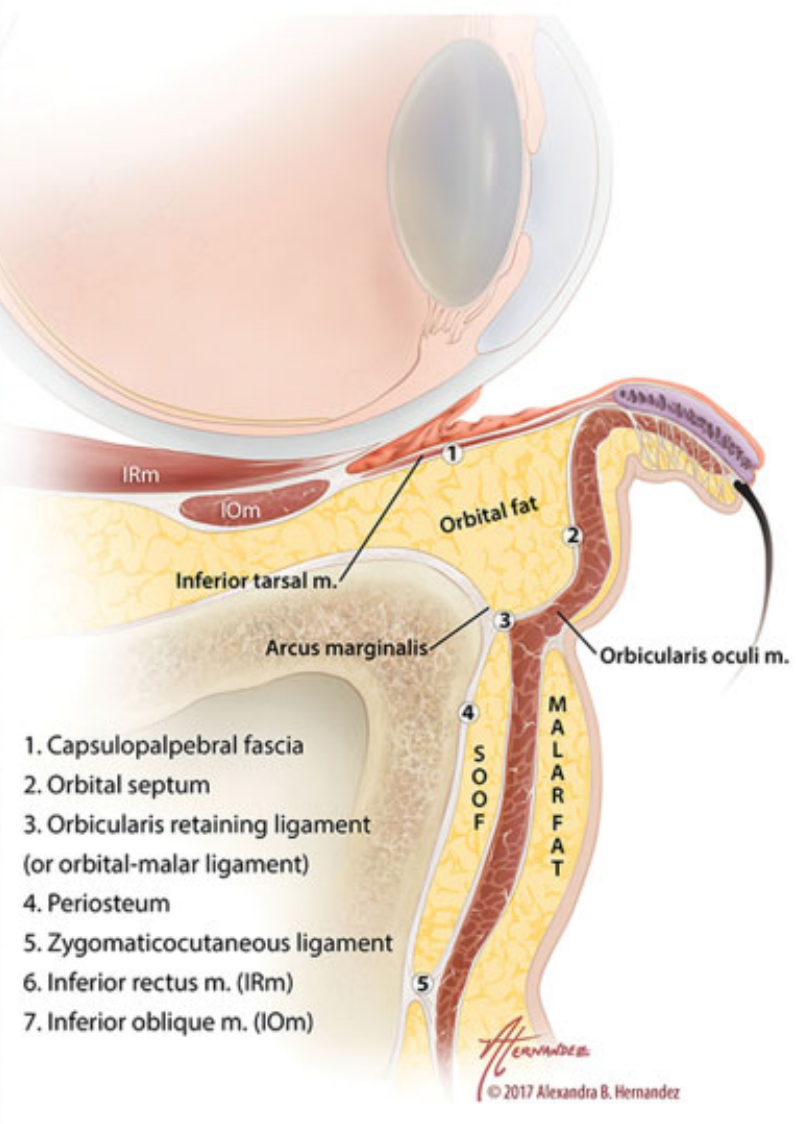

against it. Over time, this can lead to corneal ulceration and vision loss.

\section{Involutional Entropion}

The most common form of entropion is the involutional type. Several factors contribute to the development of involutional entropion. These include (1) horizontal lid laxity,(2) dehiscence of the lower lid retractors, (3) loss of vertical support due to thinning of the tarsal plate, (4) a preseptal orbicularis that overrides a smaller than average tarsal plate, and (5) enophthalmos caused by atrophy of orbital fat. ${ }^{24,25}$ Assessment of the lower lid usually shows increased lower lid laxity that is easy to evert with inferior traction. In mild cases, involutional entropion can be treated with botulinum toxin to the orbicularis muscle to weaken its activity. ${ }^{26}$ The goal of surgical correction depends on the underlying pathophysiology; therefore, proper assessment is key to a successful procedure. Horizontal laxity can be addressed via a lateral tarsal strip procedure, ${ }^{18}$ a fullthickness partial eyelid resection, ${ }^{27}$ or tightening of the inferior crus of the lateral canthal tendon. ${ }^{28}$ An overriding pretarsal orbicularis muscle can be addressed by tightening the orbicularis muscle, ${ }^{29}$ resection of the orbicularis, ${ }^{30,31}$ direct suture fixation of the orbicularis muscle, ${ }^{32,33}$ or shortening the eyelid 

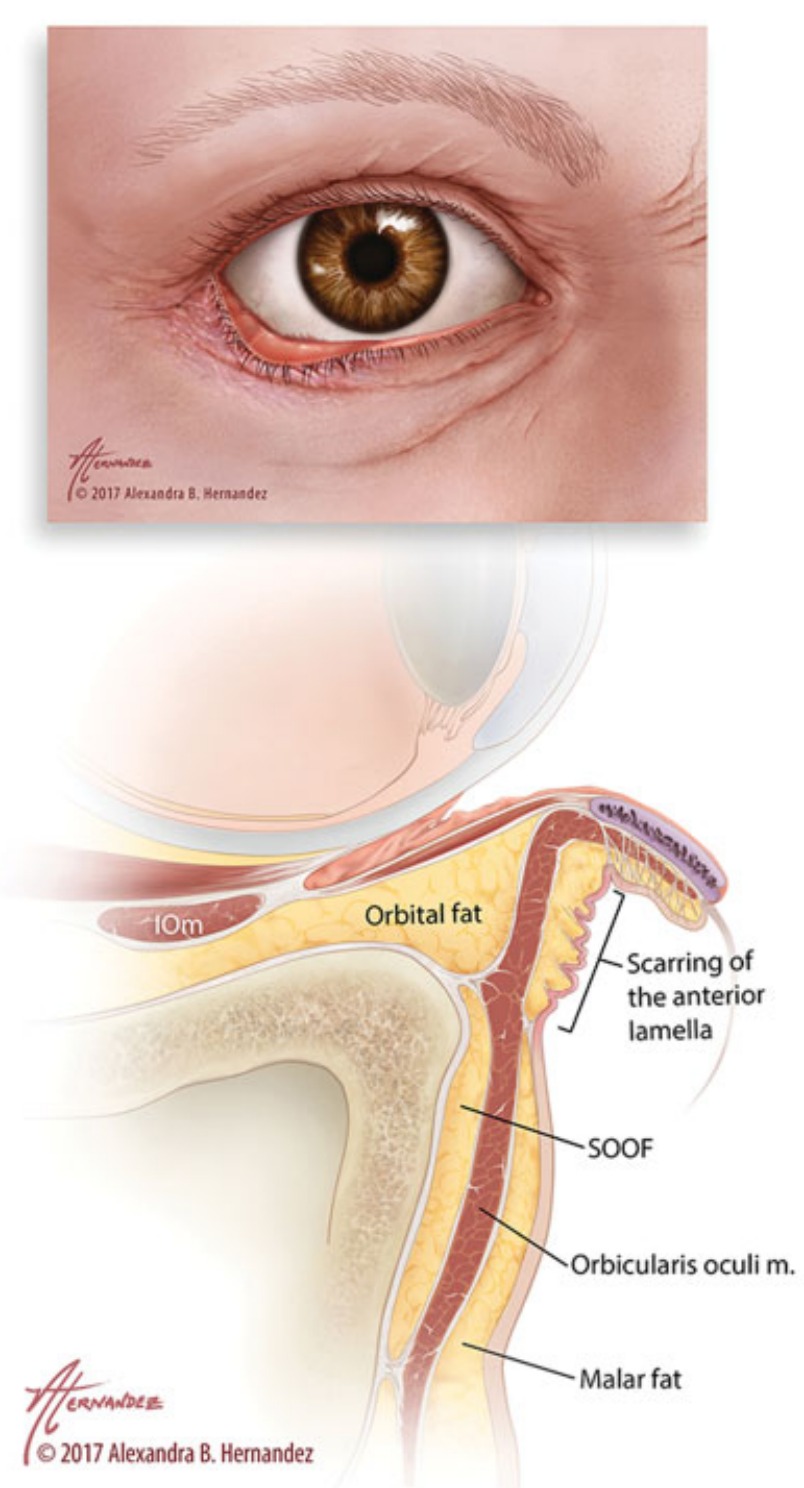

Fig. 5 Lower lid cicatricial ectropion and skin graft repair.

and suturing the skin edge to the tarsus. ${ }^{18}$ Spinelli et al describe their technique of tightening the suborbicularis septum and lateral canthus, which resulted in successful correction of entropion in 409 eyelids. ${ }^{25}$ Barnes et al described a technique that combined lateral tarsal strip and everting sutures to correct entropion that could be performed successfully by both residents and general ophthalmologists. ${ }^{34}$

\section{Cicatricial Entropion}

Cicatricial entropion results from a vertically shortened posterior lamella, usually from scarring of the conjunctiva or tarsus. Common causes are transconjunctival approach for orbital or periorbital surgery, trauma, chemical burns, conjunctival infections, or inflammation. Cause of the cicatricial entropion should be investigated as systemic inflammatory conditions may require treatment prior to surgery. Examination of the lower lid may reveal tarsal
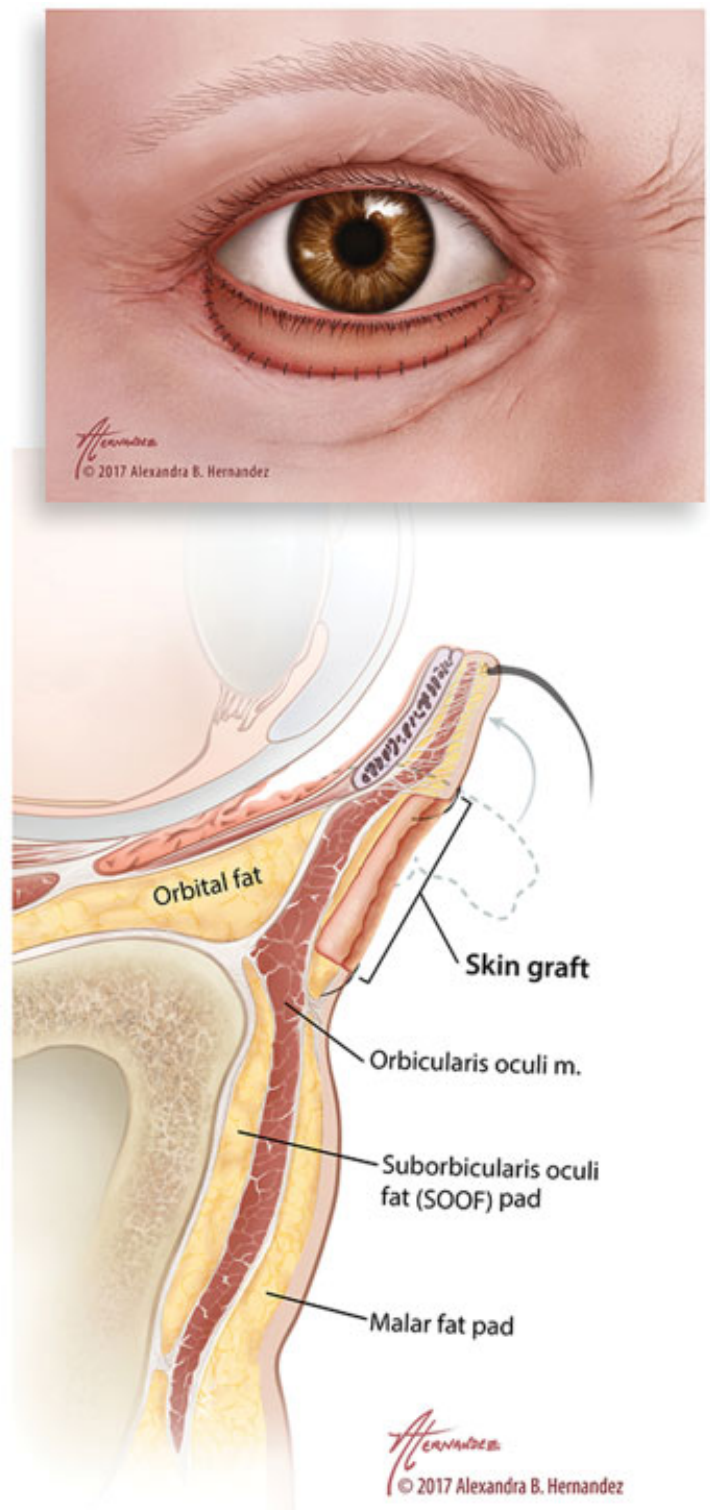

scarring with blunting and shortening of the fornices or adhesions, causing a tethered lid. The goals of treatment include anterior rotation of the lid margin, repositioning the lashes away from the cornea, and restoration of the posterior lamellar height. Surgical options include placing a mucosal spacer graft (e.g., hard palate mucosa and buccal mucosa), tarsal fracture, blepharotomy, and suturing techniques (-Fig. 6a, b). ${ }^{35-39}$

\section{Midface Suspension}

Midface descent is another cause of lower lid retraction. This may be due to age, trauma, surgery, or facial paralysis. ${ }^{13}$ The presence of a distinct lid-cheek interface, hollowed appearance of the infraorbital area, an inferiorly displaced malar fat pad, and a flattened malar eminence may be evidence of malar descent. Repositioning of the SOOF and malar fat pad can be performed via a supraperiosteal or subperiosteal midface 


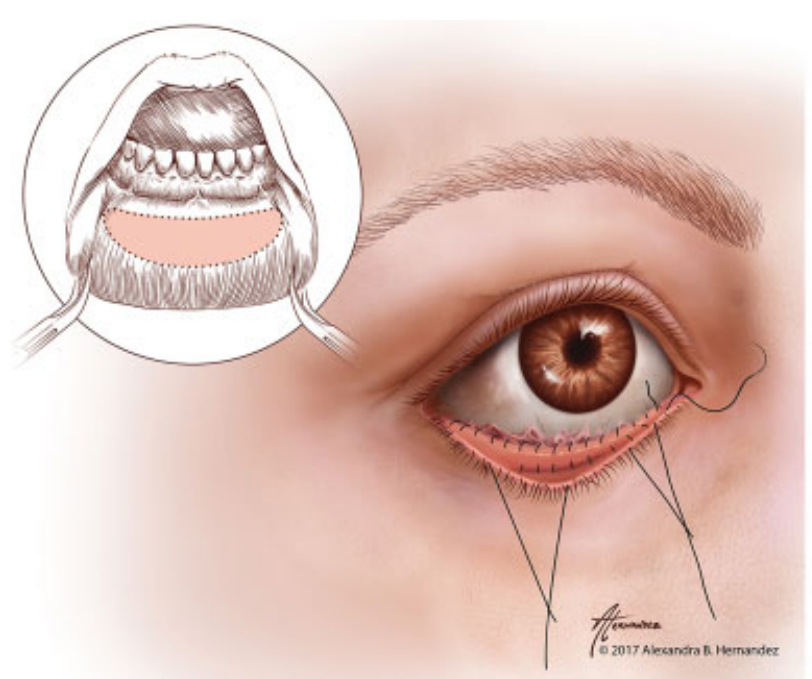

a

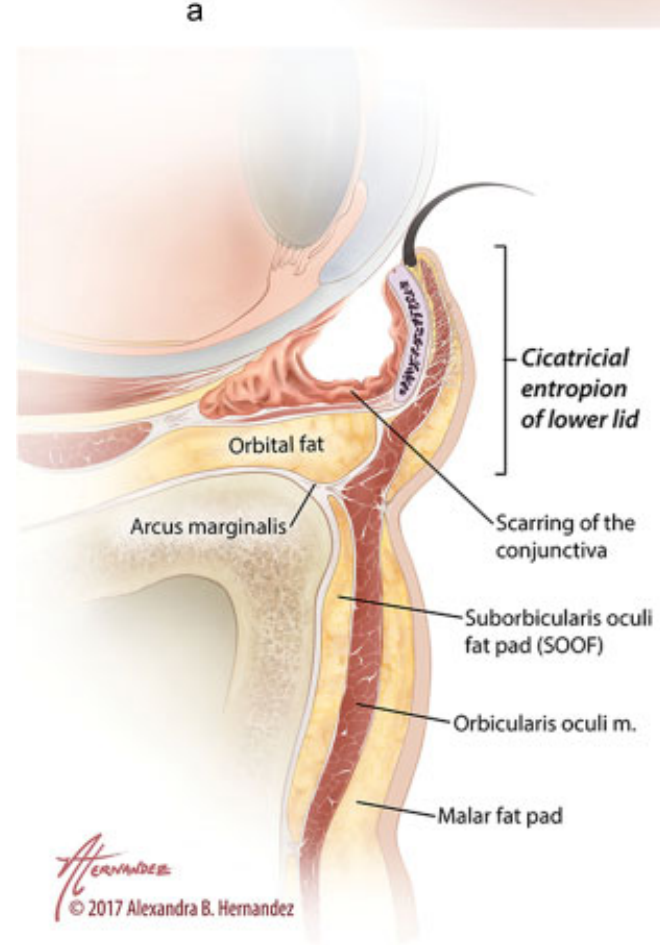

b

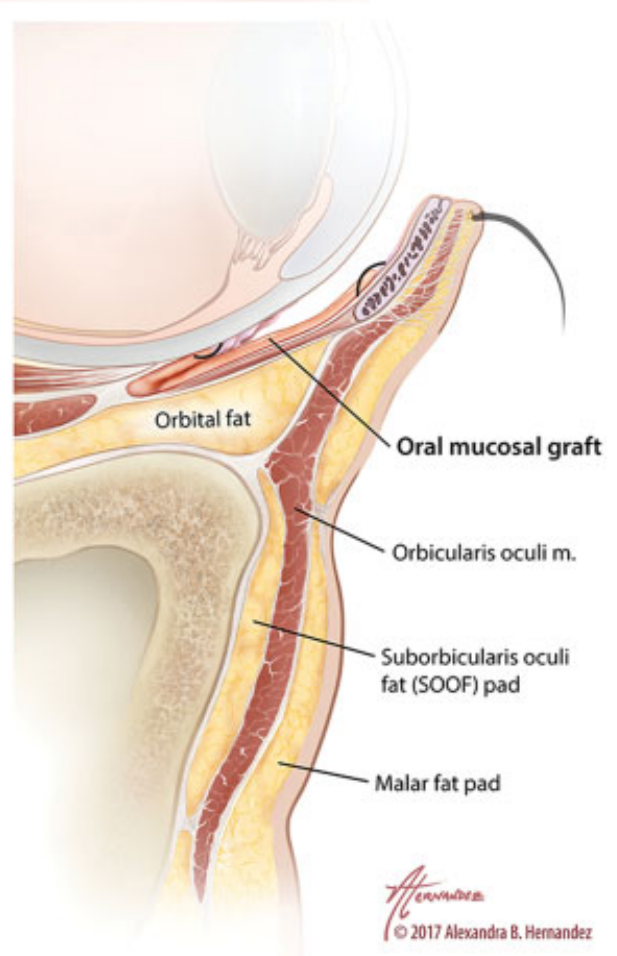

Fig. 6 (a) Mucosal graft harvest and inset for lower lid cictricial entropion. (b) Sagittal view of lower lid cictricial entropion and mucosal graft repair.

elevation via transconjunctial, transtemporal, subciliary, and endoscopic approaches ( - Fig. 7)..$^{15,40-43}$ Brown et al recently reported their results in simultaneous endoscopic midface lift and open reduction internal fixation of zygomaxillary complex fractures which resulted in better midface symmetry at follow up. ${ }^{1}$

\section{Canthal Malposition}

Canthal malposition can occur, particularly if a canthotomy and cantholysis is performed. ${ }^{44}$ Canthal malposition can lead to scleral show, tearing, and irritation of the eye. A lateral tarsal strip procedure can effectively manage lateral canthal tendon malposition. ${ }^{45}$ Medial canthal malposition can also occur with trauma, medial canthal tendon laxity, facial paralysis, and midface retraction. ${ }^{46}$ Analogous to the lateral tarsal strip procedure, a medial tarsal strip procedure may be utilized to correct medial canthal malposition. ${ }^{47}$ Elner et al described a transcaruncular plication procedure to correct medial canthal tendon laxity and position. ${ }^{46}$

\section{Conclusion}

Lower lid malposition can be a consequence of natural aging, trauma, iatrogenic causes, and other diseases. Patients with lower lid retraction symptoms can range from the annoyance of excessive tearing to rare, but catastrophic loss of vision. The lower eyelid anatomy is complex, but understanding the anatomy is crucial. When lower lid complications arise, the 


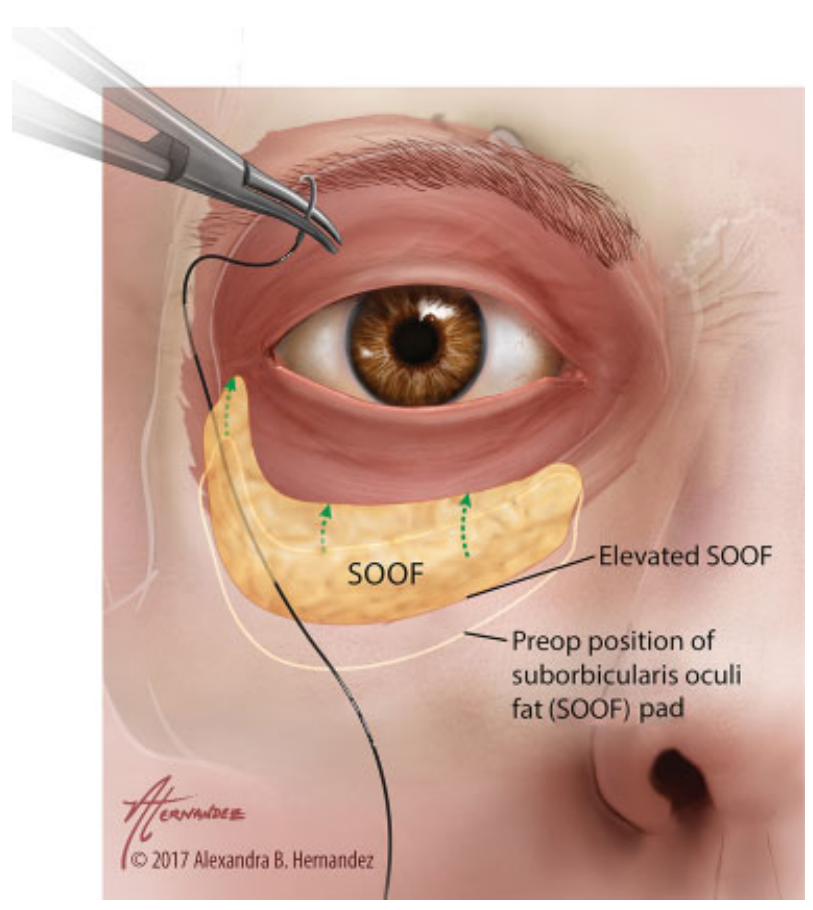

Fig. 7 Repositioning of SOOF. SOOF, suborbicularis oculi fat.

facial trauma surgeon should make every effort to identify the offending cause and correct the deficient anatomical layer to restore proper lid function and aesthetics.

\section{Conflict of Interest}

None.

\section{References}

1 Brown R, Lozada K, Kadakia S, Gordin E, Ducic Y. Prophylactic midface lift in midfacial trauma. Facial Plast Surg 2017;33(03):347-351

2 De Riu G, Meloni SM, Gobbi R, Soma D, Baj A, Tullio A. Subciliary versus swinging eyelid approach to the orbital floor. J Craniomaxillofac Surg 2008;36(08):439-442

3 Kothari NA, Avashia YJ, Lemelman BT, Mir HS, Thaller SR. Incisions for orbital floor exploration. J Craniofac Surg 2012; 23(07, Suppl 1):1985-1989

4 Raschke GF, Rieger UM, Bader RD, et al. The zygomaticomaxillary complex fracture-an anthropometric appraisal of surgical outcomes. J Craniomaxillofac Surg 2013;41(04):331-337

5 Ridgway EB, Chen C, Colakoglu S, Gautam S, Lee BT. The incidence of lower eyelid malposition after facial fracture repair: a retrospective study and meta-analysis comparing subtarsal, subciliary, and transconjunctival incisions. Plast Reconstr Surg 2009;124(05):1578-1586

6 Yamashita M, Kishibe M, Shimada K. Incidence of lower eyelid complications after a transconjunctival approach: influence of repeated incisions. J Craniofac Surg 2014;25(04):1183-1186

7 Aldekhayel S, Aljaaly H, Fouda-Neel O, Shararah AW, Zaid WS, Gilardino M. Evolving trends in the management of orbital floor fractures. J Craniofac Surg 2014;25(01):258-261

8 Raschke GF, Rieger UM, Bader RD, Schaefer O, Guentsch A, Schultze-Mosgau S. Transconjunctival versus subciliary approach for orbital fracture repair-an anthropometric evaluation of 221 cases. Clin Oral Investig 2013;17(03):933-942

9 Sand JP, Zhu BZ, Desai SC. Surgical anatomy of the eyelids. Facial Plast Surg Clin North Am 2016;24(02):89-95
10 Shorr N, Fallor MK. “Madame Butterfly" procedure: combined cheek and lateral canthal suspension procedure for post-blepharoplasty, "round eye," and lower eyelid retraction. Ophthal Plast Reconstr Surg 1985;1(04):229-35

11 Kakizaki H, Malhotra R, Madge SN, Selva D. Lower eyelid anatomy: an update. Ann Plast Surg 2009;63(03):344-351

12 Mowlavi A, Neumeister MW, Wilhelmi BJ. Lower blepharoplasty using bony anatomical landmarks to identify and avoid injury to the inferior oblique muscle. Plast Reconstr Surg 2002;110(05): 1318-1322; discussion 1323-1324

13 Patel MP, Shapiro MD, Spinelli HM. Combined hard palate spacer graft, midface suspension, and lateral canthoplasty for lower eyelid retraction: a tripartite approach. Plast Reconstr Surg 2005;115(07):2105-2114; discussion 2115-2117

14 Patipa M. The evaluation and management of lower eyelid retraction following cosmetic surgery. Plast Reconstr Surg 2000;106(02):438-453; discussion 454-459

15 Hachach-Haram N, Kirkpatrick WN. Midface-lifting: evolution, indications, and technique. Facial Plast Surg 2013;29(04):289-294

16 Hahn S, Desai SC. Lower lid malposition: causes and correction. Facial Plast Surg Clin North Am 2016;24(02):163-171

17 Jones ST, Aakalu VK, Lin AY, et al. Surgical microanatomy of lower eyelid tarsal ectropion repair with a Putterman ptosis clamp. Ophthal Plast Reconstr Surg 2017;33(04):261-263

18 Anderson RL, Gordy DD. The tarsal strip procedure. Arch Ophthalmol 1979;97(11):2192-2196

19 Fagien S. Algorithm for canthoplasty: the lateral retinacular suspension-a simplified suture canthopexy. Plast Reconstr Surg 1999;103(07):2042-2053; discussion 2054-2058

20 Jelks GW, Glat PM, Jelks EB, Longaker MT. The inferior retinacular lateral canthoplasty: a new technique. Plast Reconstr Surg 1997; 100(05):1262-1270; discussion 1271-1275

21 Lisman RD, Campbell J. Tarsal suspension canthoplasty. Aesthet Surg J 1999;19:412-423

22 Nowinski TS, Anderson RL. The medial spindle procedure for involutional medial ectropion. Arch Ophthalmol 1985;103(11): 1750-1753

23 Singa RM, Aakalu VK, Putterman AM, Epstein GA. Lower-eyelid tarsal ectropion repair with the Putterman ptosis clamp for lower-eyelid conjunctival Mueller's muscle resection and lateral tendon tuck. Ophthal Plast Reconstr Surg 2012;28(03):224-227

24 Bashour M, Harvey J. Causes of involutional ectropion and entropion-age-related tarsal changes are the key. Ophthal Plast Reconstr Surg 2000;16(02):131-141

25 Spinelli HM, Tabatabai N, Nunn DR. Correction of involutional entropion with suborbicularis septal and lateral canthal tightening. Plast Reconstr Surg 2006;117(05):1560-1567; discussion 1568-1570

26 Steel DH, Hoh HB, Harrad RA, Collins CR. Botulinum toxin for the temporary treatment of involutional lower lid entropion: a clinical and morphological study. Eye (Lond) 1997;11(Pt 4):472-475

27 Dunnington JH, Regan EF. Ziegler cautery puncture for noncicatricial entropion. Am J Ophthalmol 1966;61(5 Pt 2):1090-1092

28 Saunders DH, Shannon GM, Nicolitz E. The “corncrib” repair of senile entropion. Ophthalmic Surg 1980;11(02):128-130

29 Hill JC, Feldman F. Tissue barrier modifications of a Wheeler II operation for entropion. Arch Ophthalmol 1967;78(05):621-623

30 Corin S, Veloudios A, Harvey JT. A modification of the lateral tarsal strip procedure with resection of orbicularis muscle for entropion repair. Ophthalmic Surg 1991;22(10):606-608

31 Wheeler JM. Spastic entropion correction by orbicularis transplantation. Trans Am Ophthalmol Soc 1938;36:157-162

32 Nowinski TS. Orbicularis oculi muscle extirpation in a combined procedure for involutional entropion. Ophthalmology 1991;98 (08):1250-1256

33 Rougraff PM, Tse DT, Johnson TE, Feuer W. Involutional entropion repair with fornix sutures and lateral tarsal strip procedure. Ophthal Plast Reconstr Surg 2001;17(04):281-287 
34 Barnes JA, Bunce C, Olver JM. Simple effective surgery for involutional entropion suitable for the general ophthalmologist Ophthalmology 2006;113(01):92-96

35 Bartley GB, Kay PP. Posterior lamellar eyelid reconstruction with a hard palate mucosal graft. Am J Ophthalmol 1989;107(06):609-612

36 Baylis HI, Hamako C. Tarsal grafting for correction of cicatricial entropion. Ophthalmic Surg 1979;10(07):42-48

37 Millman AL, Katzen LB, Putterman AM. Cicatricial entropion: an analysis of its treatment with transverse blepharotomy and marginal rotation. Ophthalmic Surg 1989;20(08):575-579

38 Sodhi PK, Yadava U, Mehta DK. Efficacy of lamellar division for correcting cicatricial lid entropion and its associated features unrectified by the tarsal fracture technique. Orbit 2002;21(01):9-17

39 Wojno TH. Lid splitting with lash resection for cicatricial entropion and trichiasis. Ophthal Plast Reconstr Surg 1992;8(04):287-289

40 DeFatta R, Ducic Y. Midface lifts. Oper Tech Otolaryngol-Head Neck Surg 2007;18(03):217-232

41 Anderson RD, Lo MW. Endoscopic malar/midface suspension procedure. Plast Reconstr Surg 1998;102(06):2196-2208
42 Marshak H, Morrow DM, Dresner SC. Small incision preperiosteal midface lift for correction of lower eyelid retraction. Ophthal Plast Reconstr Surg 2010;26(03):176-181

43 Hinderer UT. Vertical preperiosteal rejuvenation of the frame of the eyelids and midface. Plast Reconstr Surg 1999;104(05): 1482-1499; discussion 1500-1501

44 Salgarelli AC, Bellini P, Landini B, Multinu A, Consolo U. A comparative study of different approaches in the treatment of orbital trauma: an experience based on 274 cases. Oral Maxillofac Surg 2010;14(01):23-27

45 Salgarelli AC, Bellini P, Multinu A, Landini B, Consolo U. Tarsal strip technique for correction of malposition of the lower eyelid after treatment of orbital trauma. Br J Oral Maxillofac Surg 2009;47 (04):298-301

46 Elner VM, Demirci H, Morton AD, Elner SG, Hassan AS. Transcaruncular medial canthal ligament plication for repair of lower eyelid malposition. Arch Ophthalmol 2007;125(03):374-379

47 Jordan DR, Anderson RL, Thiese SM. The medial tarsal strip. Arch Ophthalmol 1990;108(01):120-124 